\title{
Effect of Needle Size and Volumetric Flow Rate on Root Canal Irrigation: A Numerical Investigation
}

\author{
Mohammad Ghalandari ${ }^{1}$, Mona Malek ${ }^{2}$, Hossein Alizadeh ${ }^{3}$, Fatemeh Ghalandari ${ }^{4}$, Amir Mosavi ${ }^{5,6}$, \\ Shahaboddin Shamshirband ${ }^{7,8}$ Kwok-wing $\mathrm{Chau}^{9}$ \\ ${ }^{1}$ Faculty of Department of aerospace engineering, Sharif University of Technology, Tehran, Iran; \\ ghalandary.13518@gmail.com
}

${ }^{2}$ Dental Clinic of AmirAlam Hospital, Tehran University of Medical Science, Tehran, Iran; mona_mlk@yahoo.com

${ }^{3}$ Department of New Sciences and Technologies, Tehran University, Tehran, Iran. hos.128@gmail.com

${ }^{4}$ Student in Veterinary Medicine, Faculty of Vet-Medicine science, Lorestan University, Khorramabad, Iran; fatemeh.gh.5866@gmail.com

${ }^{5}$ Kando Kalman Faculty of Electrical Engineering, Obuda University, 1034 Budapest, Hungary; amir.mosavi@kvk.uni-obuda.hu

${ }^{6}$ School of the Built Environment, Oxford Brookes University, Oxford OX3 0BP, UK

${ }^{7}$ Department for Management of Science and Technology Development, Ton Duc Thang University, Ho Chi Minh, Vietnam

${ }^{8}$ Faculty of Information Technology, Ton Duc Thang University, Ho Chi Minh City, Vietnam

${ }^{9}$ Department of Civil and Environmental Engineering, Hong Kong Polytechnic University, Hong Kong, People's Republic of China

\begin{abstract}
Among the different applicable irrigants for root canal disinfection, sodium hypochlorite $5.25 \%$ is one of the most attractive ones. The quality of root canal disinfection is dependent on some factors such as the employed approach, type of flow rate of irrigant and the size of needle. The majority of studies in the field of root canal disinfection are experimentally carried out. In the current article, Computation Fluid Dynamic (CFD) is used for modeling the antimicrobial liquid flow in the root canal and evaluate the effects of needle size and flow rate. Two needles, G28 and G30, are used for irrigation in three volumetric rates of flow including $0.10 \mathrm{~mL} / \mathrm{s}, 0.20 \mathrm{~mL} / \mathrm{s}$ and $0.30 \mathrm{~mL} / \mathrm{s}$. The results of numerical simulations revealed the improved quality of root canal disinfection by augmentation in the rate of flow and decrease in the inner diameter of the needle. According to the outcomes of the modeling, the highest average wall shear stress obtained in the case of using G28 needle and $30 \mathrm{~mL} / \mathrm{s}$ flow rate, which was approximately $10.21 \mathrm{~Pa}$.
\end{abstract}

Keywords: Root Canal, Irrigation, CFD, Dentistry

\section{Introduction}

In root canal therapy it is crucial to decrease bacterial population which colonize the root canal as much as possible [1]. The most conventional approach used for disinfecting the root canal is employing 
antimicrobial agents for irrigating. The irrigation performance can be improved by some methods such as sonically or ultrasonically activations [1]. Several agents are applicable as irrigant in root canal disinfection such as silver Nano fluid, sodium hypochlorite and chlorhexidine digluconate (CHX) [2,3]. Among them, sodium hypochlorite is one of the most conventional ones due to its favorable performance in eliminating the microorganisms. In a study performed by Singh et al. [4], different irrigants including sodium hypochlorite, morinda citrifolia juice, propolis and chlorhexidine were examined to investigate their performance in Candida albicans (C. albicans) and Enterococcus feacalis (E. feacalis) removal. Their observations proved that utilizing sodium hypochlorite and chlorhexidine was more effective for root canal disinfection. Various sodium hypochlorite concentrations are employed for root canal therapy while $1.25 \%$, $2.5 \%$ and $5.25 \%$ are the most applied ones [5,6]. The performance of root canal disinfection by employing irrigant can be modified by applying activation techniques. According to the outcomes of a research conducted by Eneide et al. [7] employing passive sonic and ultrasonic activation approaches in the case of utilizing both sodium hypochlorite 5.25\% and EDTA $17 \%$ as irrigants, led to improved effectiveness of the disinfection procedure.

Due to the difficulties of the experimental studies and their time consuming feature, efficient computational and numerical methods have been developed in recent decades [8-11]. Different computational methods are utilized in engineering systems to predict their performance and model their behavior [12-16]. Computational Fluid Dynamic (CFD) is broadly employed for heat and fluid modeling in various systems such as turbomachines [17], heat exchangers [18], renewable energy technologies [19,20], and etc. studies have demonstrated that by employing CFD it is possible to model the behavior and performance of the systems with acceptable accuracy. For instance, Pakatchian et al. showed the maximum relative deviation between the predicted and measured static pressure of multistage compressor was approximately 7.5\% [17]. In addition to engineering problems, CFD have been applied in the fields of medical and dental sciences in recent years [21]. As an example, Ghalandari et al. [22] employed CFD to numerically investigate the flow of a nanofluidic irrigant. $\mathrm{Ag} /$ water, inside a root canal. In their study, impacts of nanofluid concentration and volumetric flow rate were asses. Their results showed that increase in the solid phase volume fraction of the nanofluidic irrigant and the rate of antimicrobial liquid injection led to increment in the wall shear stress of the canal, which means improved condition for disinfection.

In the previous study, the effect of nanofluidic irrigant concentration and injection rate on the fluid circulation and wall shear stress of the canal was analyzed; however, other factors can influence the irrigation procedure such as the type of needle and its size. In this regard, CFD is employed in the current article to investigate the impact of needle size on the fluid flow features and wall shear stress in the case of using sodium hypochlorite $5.25 \%$, which is one of the most convention used disinfection liquids in endodontic [23], as the irrigant. In addition, three volumetric flow rate for injection are considered to evaluate its effect more comprehensively. Finally, according to the obtained results, some suggestions are represented to improve the quality of root canal disinfection by using the conventional methods.

\section{Materials and methods}

As the first stage of the modeling, the geometry of the root canal considered similar to the previous study carried out by Kocharian [24]. In this model, the canal length equals to $18 \mathrm{~mm}$ and the apical and orifice diameters are equal to $1.57 \mathrm{~mm}$ and $0.45 \mathrm{~mm}$, respectively. Two needles, including G28 and G30 are used for modeling in order to find the impact of needle size on the root canal fluid flow. The needle length used for the modeling assumed to be equal to $31 \mathrm{~mm}$, which is similar to the dimension of previous research 
[22]. In addition, the injection height considered $3 \mathrm{~mm}$ from the bottom of apical part. Sodium hypochlorite $5.25 \%$, which is an efficient and conventional solution for root canal disinfection, is used as the irrigant in the present article.

In CFD, it is required to use meshed domain in order to solve the equations and obtain the fluid flow features. In this regard, structured mesh is employed. According to the grid independency evaluation, the number of mesh in optimum condition is approximately 720,000 . The meshed model is represented in Figure 1.

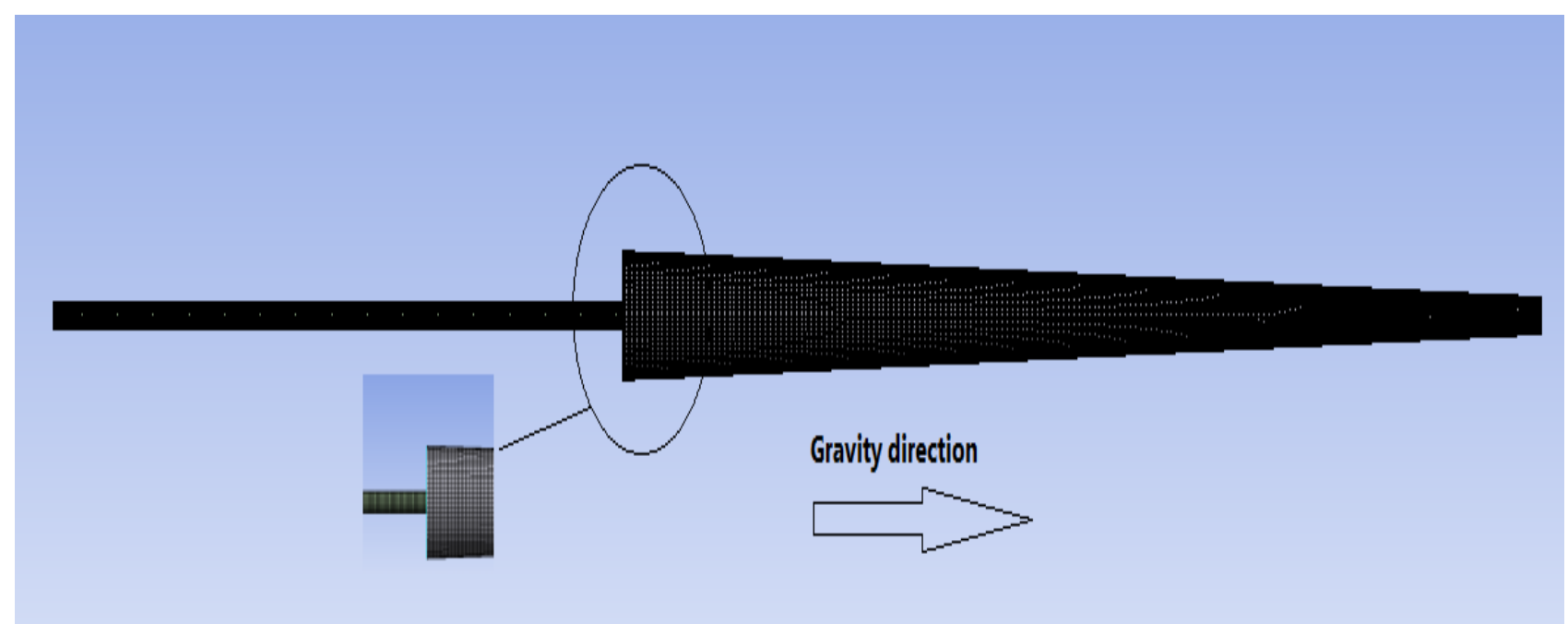

Figure 1 The model with structured mesh

Both mass and momentum conservation equations must be solved to find the liquid flow features inside the canal. Mass conservation equation is defined as Equation (1):

$$
\frac{\partial \rho}{\partial t}+\nabla \cdot(\rho \vec{v})=S_{m}
$$

Where $\rho, S_{m}$, and $\vec{v}$ denote the density of the liquid, mass source/sink, and the velocity vector, respectively. The specific gravity of the irrigant assumed to be 1.08 . The momentum conservation equation is represented as:

$$
\frac{\partial(\rho \vec{v})}{\partial t}+\nabla \cdot(\rho \vec{v} \cdot \vec{v})=-\nabla p+\nabla \cdot \overline{\bar{\tau}}+\rho \vec{g}+\vec{F}
$$

In this equation, $\rho \vec{g}$ and $\mathrm{p}$ refer to the body force and field of pressure in the fluid domain. In addition, $\overline{\bar{\tau}}$ and $\vec{F}$ denote the stress tensor and external force, respectively. The gravity force direction is represented in Figure 1. The tensor of stress is defined as:

$$
\overline{\bar{\tau}}=\mu\left[\left(\nabla \cdot \vec{v}+\nabla \cdot \vec{v}^{T}\right)-\frac{2}{3} \nabla \cdot \vec{v} \cdot \overline{\bar{I}}\right]
$$

In Equation (3), $\overline{\bar{I}}$ is the unit tensor and $\mu$ refers to the fluid dynamic viscosity. The dynamic viscosity of the irrigant considered equal to $1.53 \mathrm{Cps}$ at $25^{\circ} \mathrm{C}$ as measured in the study carried out by Gopikrishna et al. [25]. Incompressible and steady flow is assumed for the antimicrobial liquid inside the canal. The 
volumetric flow rate used at the inlet of needle while pressure used for the fluid outlet, at the orifice of the canal. In addition, it is assumed that no-slip condition exist at the circumferential wall of the canal.

In order to numerically solve the equations, ANSYS CFX 17 is applied. In the current research, k- $\varepsilon$ turbulent model is used which is represented in details in Ref [26]. RMSE lower than $10^{-5}$ for the equations considered as the convergence criterion.

\section{Results and discussion}

In the first step of the study, the velocity contours in different conditions is obtained in order to obtain deep insight into the fluid circulation inside the root canal. As illustrated in Figures 2 to 3, the maximum velocity of the irrigant in the canal in the case of using G30 needle is higher than G28, which is due to smaller size of G30 needle. Since the volumetric flow rate of the irrigant is constant, reduction in the inner diameter of the needle results in increase in the average and maximum velocity. The maximum velocities of the antimicrobial liquid inside the canal increase from $5.77 \mathrm{~m} / \mathrm{s}$ and $4.29 \mathrm{~m} / \mathrm{s}$ to $17.81 \mathrm{~m} / \mathrm{s}$ and $13.25 \mathrm{~m} / \mathrm{s}$ in the cases of using G30 and G28 needles, respectively. In addition, according to the represented contours, it can be concluded that the highest velocity value inside the canal is obtained in the vicinity of needle outlet, while it approaches to zero at the orifice of the canal. Based on the obtained values for the velocities, the irrigant circulation inside the root canal will be enhanced by reducing the internal size of needle and increasing the volumetric flow rate.
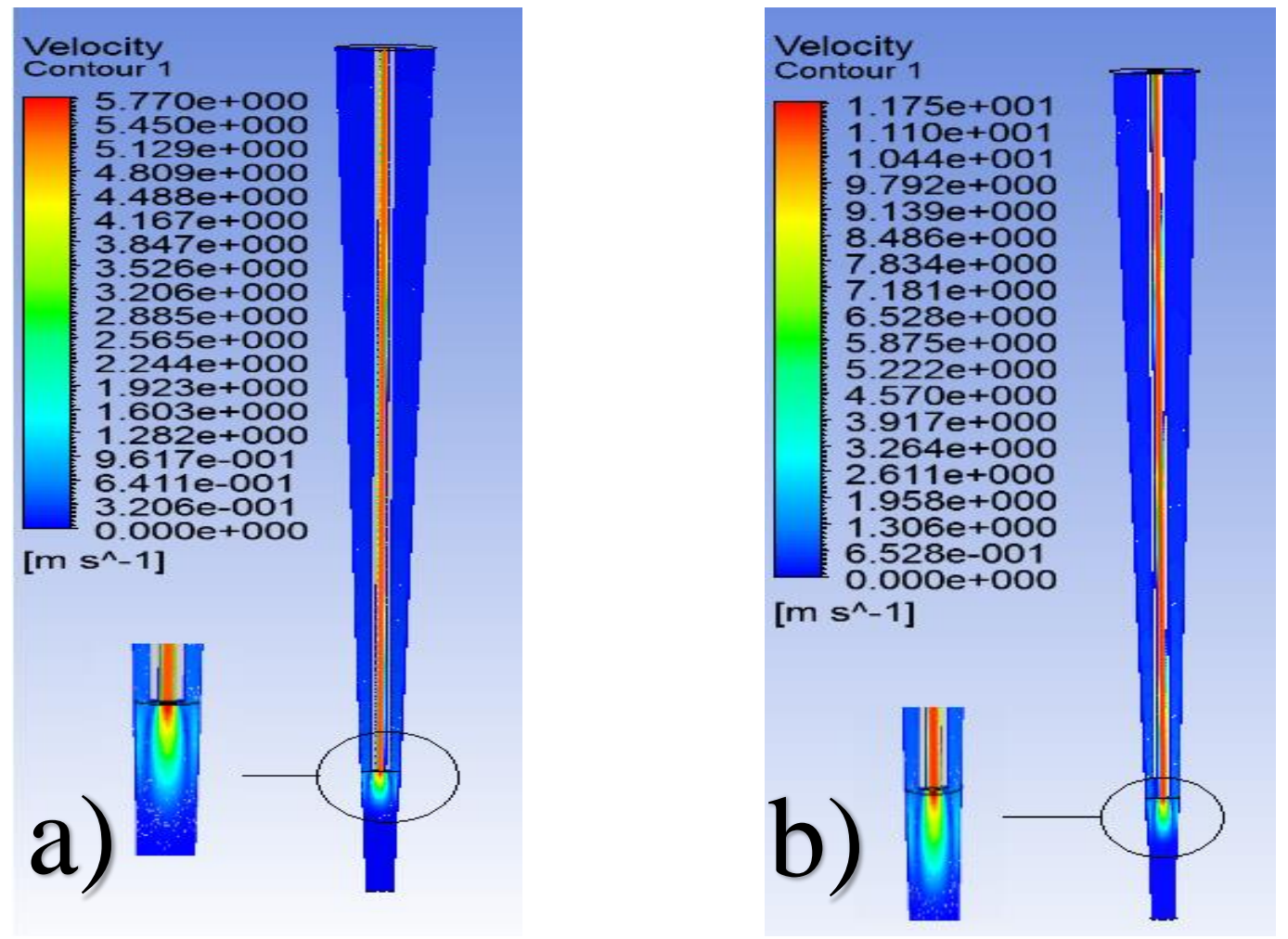


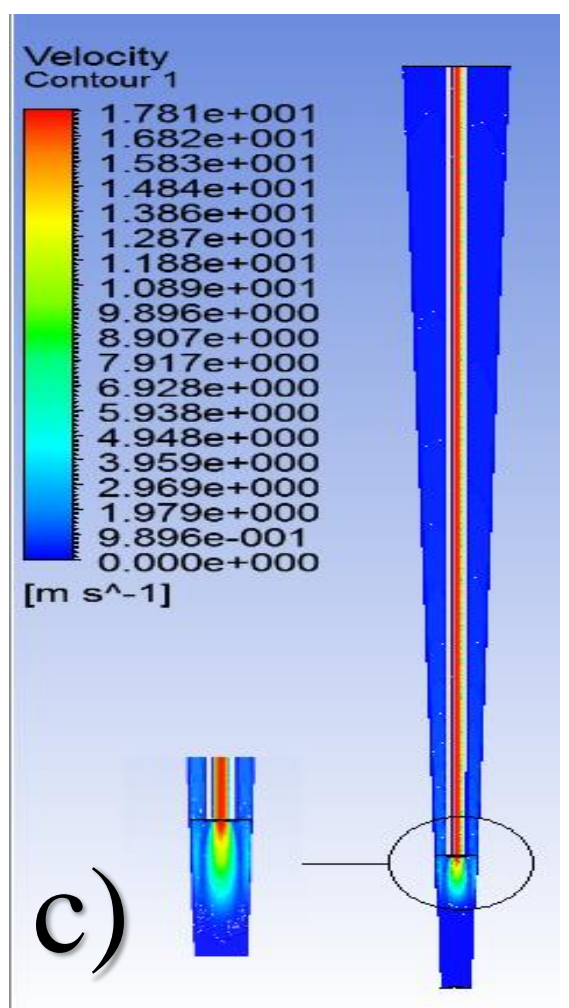

Figure 2 Velocity contours for $\mathrm{G} 30$ needle in the cases of volumetric flow rate equal to a) $10 \mathrm{~mL} / \mathrm{s}, \mathrm{b}) 20 \mathrm{~mL} / \mathrm{s}, \mathrm{c}) 30 \mathrm{~mL} / \mathrm{s}$
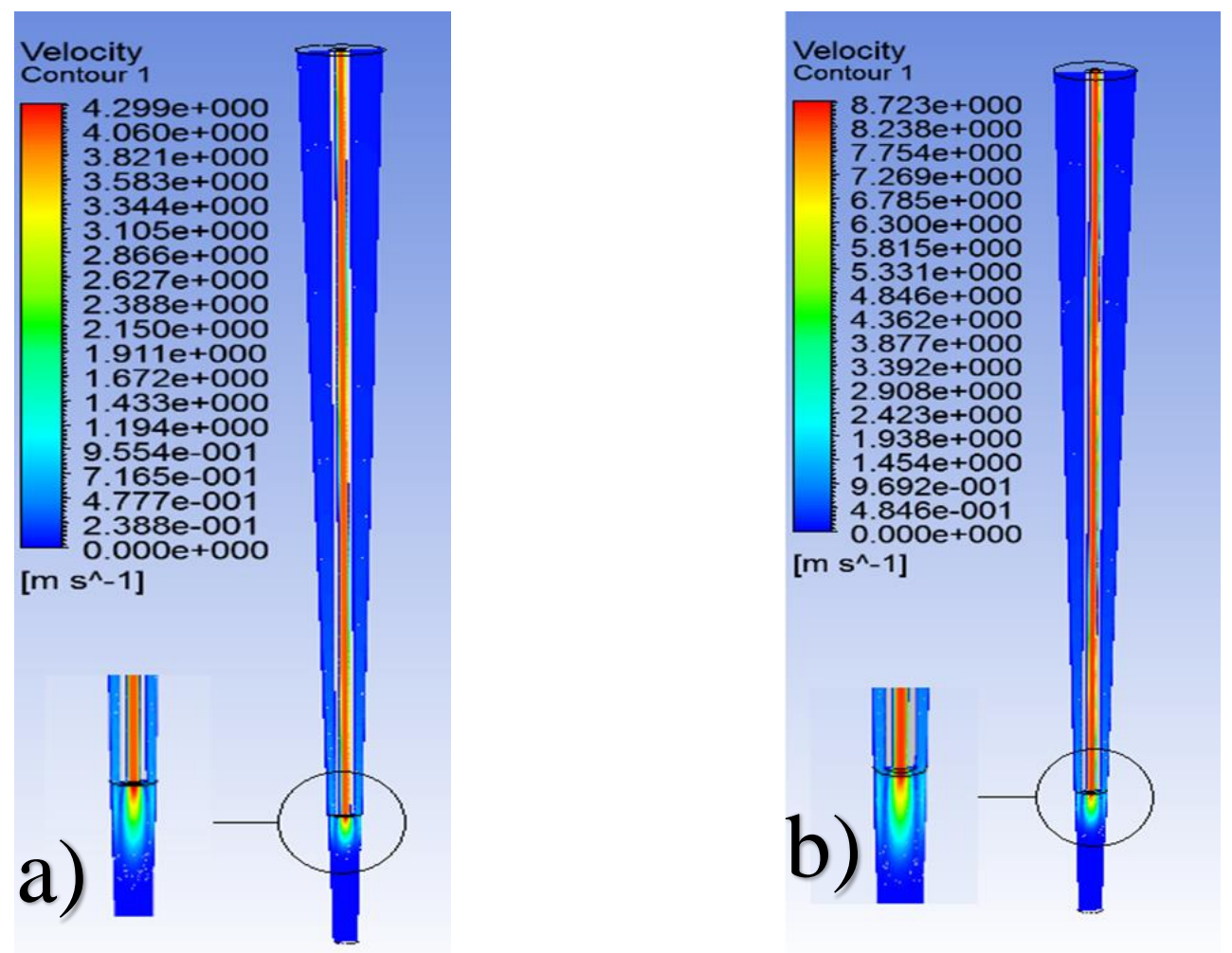


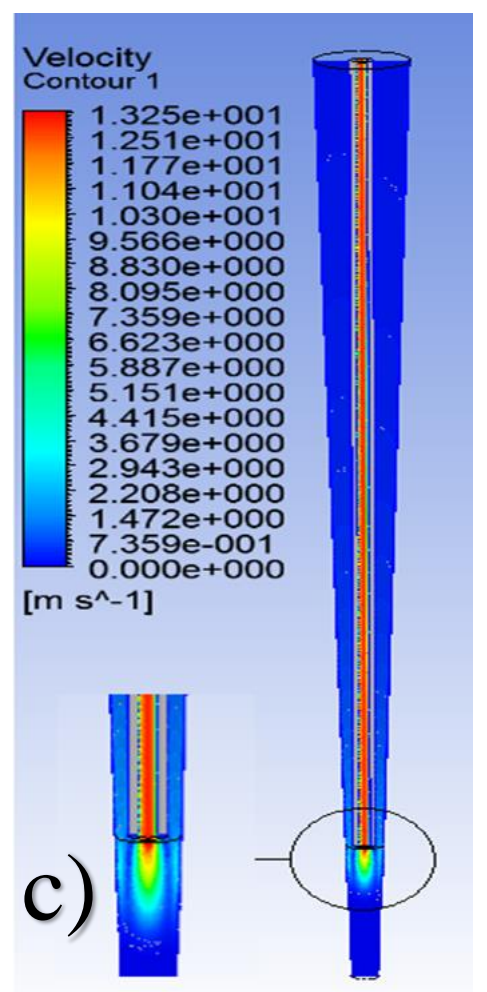

Figure 3 Velocity contours for G28 needle in the cases of volumetric flow rate equal to a) $10 \mathrm{~mL} / \mathrm{s}, \mathrm{b}) 20 \mathrm{~mL} / \mathrm{s}, \mathrm{c}) 30 \mathrm{~mL} / \mathrm{s}$

Another factor which must be considered in order to assess the quality of root canal irrigation is wall shear stress. Increment in wall shear stress denotes that the quality of disinfection is improved. In the previous study it was concluded that increase in dynamic viscosity and volumetric flow rate leads to enhancement in wall shear stress. As shown in Figures 4 and 5, by increasing the rate of flow from $0.10 \mathrm{~mL} / \mathrm{s}$ to 0.30 $\mathrm{mL} / \mathrm{s}$, the maximum wall shear stress on the outer surface of the root canal increases from approximately 52.29 $\mathrm{Pa}$ and 39.9 $\mathrm{Pa}$ to $408.5 \mathrm{~Pa}$ and $311.7 \mathrm{~Pa}$, in the cases of employing G30 and $\mathrm{G} 28$ needles, respectively. Improvement in wall shear stress by using G30 instead of G28 is due to velocity increase inside the investigated canal. Since it is assumed that no-slip condition exists at the canal wall, increment in the velocity of irrigant inside the mentioned canal means enhancement in the velocity gradient, leading to increment in the wall shear stress. The effect of volumetric flow rate on the wall shear stress is similar, which means that flow rate increment results in augmentation in both velocity and shear stress on the canal wall due to increment in the velocity gradient. 

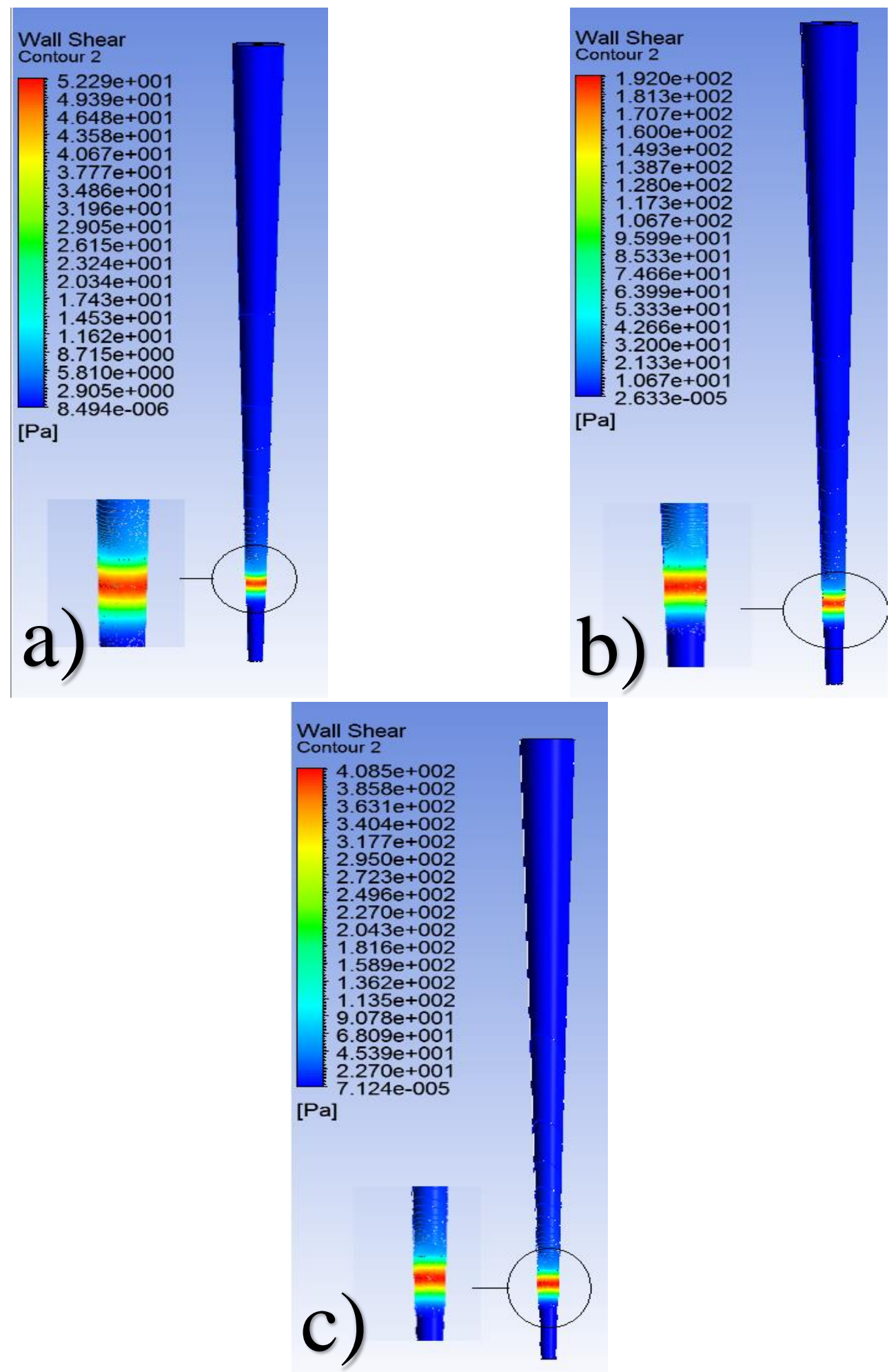

Figure 4 Wall shear stress in the cases of using $G 30$ needle flow rate equal to a) $10 \mathrm{~mL} / \mathrm{s}, b) 20 \mathrm{~mL} / \mathrm{s}, \mathrm{c}) 30 \mathrm{~mL} / \mathrm{s}$ 

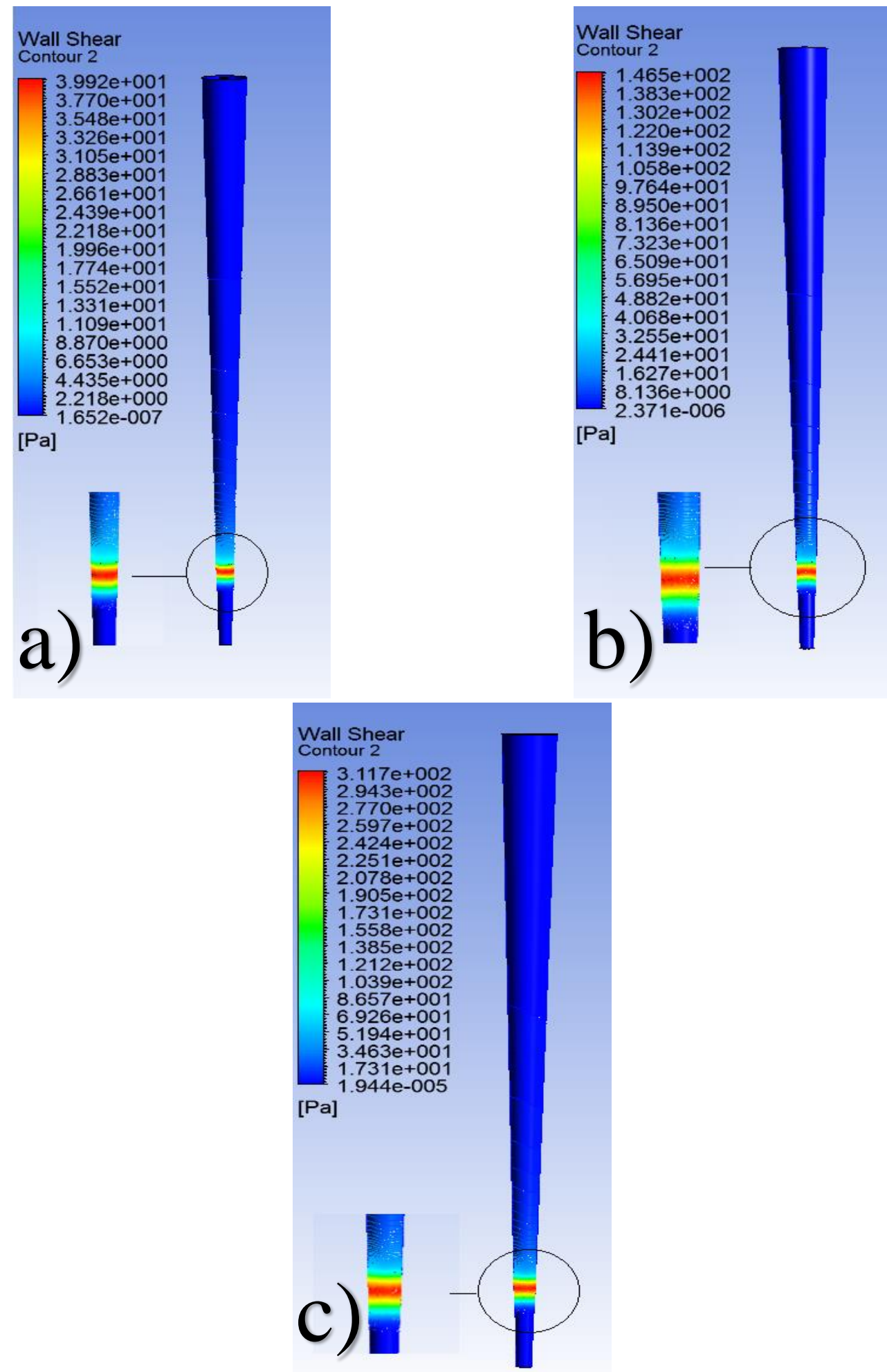

Figure 5 Wall shear stress in the cases of using $\mathrm{G} 28$ needle flow rate equal to a) $10 \mathrm{~mL} / \mathrm{s}, b) 20 \mathrm{~mL} / \mathrm{s}, \mathrm{c}) 30 \mathrm{~mL} / \mathrm{s}$

The impacts of needle size and the rate of irrigant injection on the average shear stress on outer surface of the canal wall are represented in Figure 6. As illustrated in Figure 6, the average wall shear stresses for G28 needle are approximately $1.15 \mathrm{~Pa}, 4.04 \mathrm{~Pa}$, and $8.49 \mathrm{~Pa}$ in the cases of flow rate equal to $0.10 \mathrm{~mL} / \mathrm{s}, 0.20$ 
$\mathrm{mL} / \mathrm{s}$ and $0.30 \mathrm{~mL} / \mathrm{s}$, respectively. These values in the case of using $\mathrm{G} 30$ needle increase to $1.3 \mathrm{~Pa}, 4.75 \mathrm{~Pa}$, and 10.21 Pa, respectively. According to the determined values for average wall shear stress, this quantity increases by increment in the volumetric flow rate and reduction in the needle inner diameter.

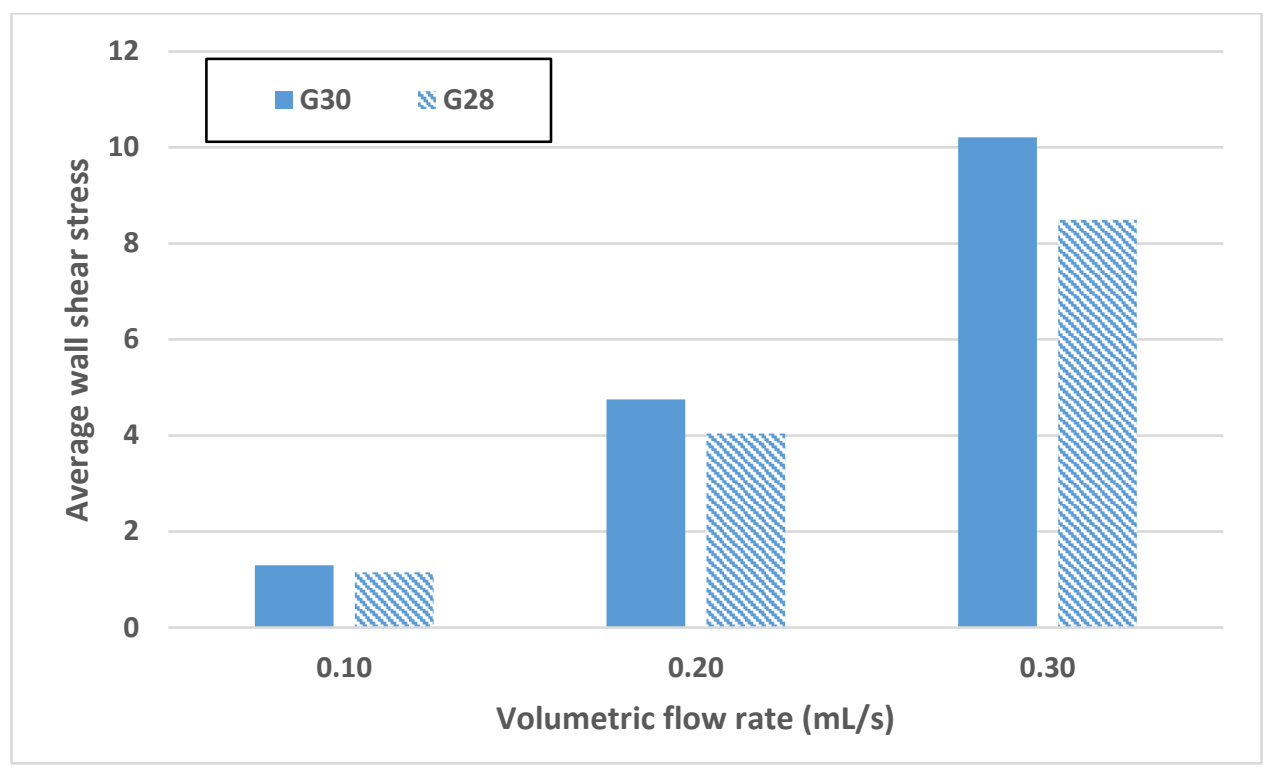

Figure 6 Average wall shear stress for G28 and G30 needles in different volumetric flow rates

In order to summarize the outcomes of the current study, it should be noted that using needles with reduced inner diameter is preferred due to augmentation in the velocity and wall shear stress. Increment in the velocity of irrigant leads to its more favorable circulation inside the root canal, which means enhanced disinfection. Moreover, both wall canal shear stress and liquid velocity in the canal are increased when the needle size inner diameter decreases, which is another reason indicating improvement in the ability of the irrigant in eliminating the microorganisms. Future researches are recommended to assess the other factors affecting the irrigant fluid flow inside the canal and other types of irrigant. In addition, other shapes of root canal, such as curved-type, should be considered.

\section{Conclusion}

In this article, the flow of a conventional irrigant, sodium hypochlorite 5.25\%, inside a root canal is numerically investigated. The impacts of volumetric flow rate of irrigant injection and the needle size on the velocity and wall shear stress are analyzed and explained. Based on the numerical simulation, following results are concluded:

- Maximum velocity of irrigant inside the root increases from $5.77 \mathrm{~m} / \mathrm{s}$ to $17.81 \mathrm{~m} / \mathrm{s}$ and from 4.29 $\mathrm{m} / \mathrm{s}$ to $13.25 \mathrm{~m} / \mathrm{sin}$ the case of using G30 and G28 needle when the rate of flow increases from 0.10 $\mathrm{mL} / \mathrm{s}$ to $0.30 \mathrm{~mL} / \mathrm{s}$, respectively.

- The maximum wall shear stress on the outer surface of the root canal obtained in $30 \mathrm{~mL} / \mathrm{s}$ volumetric flow rate which are approximately $408.5 \mathrm{~Pa}$ and $311.7 \mathrm{~Pa}$ in the cases of using $\mathrm{G} 30$ and G28 needles, respectively.

- Average wall shear stress on the outer surface of root canal improves by increasing the volumetric flow rate and decreasing the needle size. 
- Since increase in wall shear stress results in more efficient disinfection, reduction in the size of needle is suggested.

- Future studies are recommended to focus on the shape of needle tip and injection height to get more favorable insight into the antimicrobial liquids flow inside the root canal.

\section{References}

[1] Hage W, De Moor RJG, Hajj D, Sfeir G, Sarkis DK, Zogheib C. Impact of Different Irrigant Agitation Methods on Bacterial Elimination from Infected Root Canals. Dent J 2019;7:64. doi:10.3390/dj7030064.

[2] Zandi H, Petronijevic N, Mdala I, Kristoffersen AK, Enersen M, Rôças IN, et al. Outcome of Endodontic Retreatment Using 2 Root Canal Irrigants and Influence of Infection on Healing as Determined by a Molecular Method: A Randomized Clinical Trial. J Endod 2019. doi:10.1016/j.joen.2019.05.021.

[3] Akbarianrad N, Mohammadian F, Alhuyi Nazari M, Rahbani Nobar B. Applications of nanotechnology in endodontic: A Review. Nanomedicine J 2018;5:121-6. doi:10.22038/NMJ.2018.005.0001.

[4] Singh M, Singh S, Salgar AR, Prathibha N, Chandrahari N, Swapna LA. An In Vitro Comparative Evaluation of Antimicrobial Efficacy of Propolis, Morinda Citrifolia Juice, Sodium Hypochlorite and Chlorhexidine on Enterococcus faecalis and Candida albicans. J Contemp Dent Pract 2019;20:40-5.

[5] TORABINEJAD M, CHO Y, KHADEMI A, BAKLAND L, SHABAHANG S. The Effect of Various Concentrations of Sodium Hypochlorite on the Ability of MTAD to Remove the Smear Layer. J Endod 2003;29:233-9. doi:10.1097/00004770-200304000-00001.

[6] MOORER WR, WESSELINK PR. Factors promoting the tissue dissolving capability of sodium hypochlorite. Int Endod J 1982;15:187-96. doi:10.1111/j.1365-2591.1982.tb01277.x.

[7] Eneide C, Castagnola R, Martini C, Grande NM, Bugli F, Patini R, et al. Antibiofilm Activity of Three Different Irrigation Techniques: An in Vitro Study. Antibiotics 2019;8:112. doi:10.3390/antibiotics8030112.

[8] Ramezanizadeh M, TAYEBI R, SAEIDI M. Large eddy simulation of multiple jets into a cross flow. Sci Iran 2007;14:240-50.

[9] Baghban A, Kahani M, Nazari MA, Ahmadi MH, Yan W-M. Sensitivity analysis and application of machine learning methods to predict the heat transfer performance of CNT/water nanofluid flows through coils. Int J Heat Mass Transf 2019;128:825-35.

doi:10.1016/J.IJHEATMASSTRANSFER.2018.09.041.

[10] Wu Z, Li C, Cao Y. Numerical Simulation of Rotor-Wing Transient Interaction for a Tiltrotor in the Transition Mode. Mathematics 2019;7:116. doi:10.3390/math7020116.

[11] Qin Y, Liang J, Yang H, Deng Z. Gas permeability of pervious concrete and its implications on the application of pervious pavements. Measurement 2016;78:104-10. doi:10.1016/J.MEASUREMENT.2015.09.055.

[12] Farhadi-Azar R, Ramezanizadeh M, Taeibi-Rahni M, Salimi M. Compound Triple Jets Film Cooling Improvements via Velocity and Density Ratios: Large Eddy Simulation. J Fluids Eng 2011;133:031202. doi:10.1115/1.4003589. 
[13] Ahmadi MH, Sadeghzadeh M, Raffiee AH, Chau K. Applying GMDH neural network to estimate the thermal resistance and thermal conductivity of pulsating heat pipes. Eng Appl Comput Fluid Mech 2019;13:327-36. doi:10.1080/19942060.2019.1582109.

[14] Ramezanizadeh M, Taeibi-Rahni M, Saidi MH. Investigation of density ratio effects on normally injected cold jets into a hot cross flow. Arch Appl Mech 2007;77:835-47. doi:10.1007/s00419007-0132-2.

[15] Qin Y. Pavement surface maximum temperature increases linearly with solar absorption and reciprocal thermal inertial. Int J Heat Mass Transf 2016;97:391-9. doi:10.1016/J.IJHEATMASSTRANSFER.2016.02.032.

[16] Qin Y, Liang J, Tan K, Li F. The amplitude and maximum of daily pavement surface temperature increase linearly with solar absorption. Road Mater Pavement Des 2017;18:440-52. doi:10.1080/14680629.2016.1162732.

[17] Pakatchian MR, Saeidi H, Ziamolki A. CFD-based blade shape optimization of MGT-70(3)axial flow compressor. Int J Numer Methods Heat Fluid Flow 2019:HFF-10-2018-0603. doi:10.1108/HFF-10-2018-0603.

[18] Ramezanizadeh M, Alhuyi Nazari M, Ahmadi MH, Chau K. Experimental and numerical analysis of a nanofluidic thermosyphon heat exchanger. Eng Appl Comput Fluid Mech 2019;13:40-7. doi:10.1080/19942060.2018.1518272.

[19] Alizadeh H, Ghasempour R, Shafii MB, Ahmadi MH, Yan W-M, Nazari MA. Numerical simulation of PV cooling by using single turn pulsating heat pipe. Int J Heat Mass Transf 2018;127:203-8. doi:10.1016/J.IJHEATMASSTRANSFER.2018.06.108.

[20] Ramezanizadeh M, Alhuyi Nazari M, Hossein Ahmadi M, Chen L. A review on the approaches applied for cooling fuel cells. Int J Heat Mass Transf 2019;139:517-25. doi:10.1016/J.IJHEATMASSTRANSFER.2019.05.032.

[21] Tang AYS, Fan Y, Cheng SWK, Chow KW. Biomechanical Factors Influencing Type B Thoracic Aortic Dissection: Computational Fluid Dynamics Study. Eng Appl Comput Fluid Mech 2012;6:622-32. doi:10.1080/19942060.2012.11015447.

[22] Ghalandari M, Mirzadeh Koohshahi E, Mohamadian F, Shamshirband S, Chau KW. Numerical simulation of nanofluid flow inside a root canal. Eng Appl Comput Fluid Mech 2019;13:254-64. doi:10.1080/19942060.2019.1578696.

[23] Kucher M, Dannemann M, Modler N, Hannig C, Weber M-T. Effects of Endodontic Irrigants on Material and Surface Properties of Biocompatible Thermoplastics. Dent J 2019;7:26. doi:10.3390/dj7010026.

[24] Kocharian T. Root Canal Irrigation- An engineering analysis using Computational Fluid Dynamics. University of Toronto, n.d.

[25] Gopikrishna V, Ashok P, Kumar AP, Narayanan LL. Influence of temperature and concentration on the dynamic viscosity of sodium hypochlorite in comparison with 17\% EDTA and $2 \%$ chlorhexidine gluconate: An in vitro study. J Conserv Dent 2014;17:57-60. doi:10.4103/09720707.124142 .

[26] Raisee M, Noursadeghi a., Hejazi B, Khodaparast S, Besharati S. Simulation of Turbulent Heat Transfer In Jet Impingement of Air Flow Onto A Flat Wall. Eng Appl Comput Fluid Mech 2007;1:314-24. doi:10.1080/19942060.2007.11015202. 